\title{
PERSPECTIVA DEL DERECHO DEL MEDIO AMBIENTE Y DE LAS POLÍTICAS AMBIENTALES DE LA UNIÓN EUROPEA
}

\section{(PRIMER SEMESTRE 2019)}

\author{
Pol PALLÀs SECALL \\ Investigador predoctoral \\ Universitat de Barcelona
}


Sumario: 1. Introducción. 2. Actos jurídicos en el ámbito de la política europea del medio ambiente. 2.1. Actos legislativos. a) Reglamentos. b) Directivas. c) Decisiones. 2.2. Actos delegados. a) Reglamentos delegados. b) Directivas delegadas. 2.3. Actos de ejecución. a) Reglamentos de ejecución. b) Decisiones de ejecución. 2.4. Acuerdos internacionales y posiciones en organismos internacionales. 3. Otras actividades y actos en el ámbito de la política europea del medio ambiente. 3.1 Consultas públicas. 3.2. Resoluciones no legislativas del Parlamento Europeo. 3.3. Informes y comunicaciones de la Comisión Europea. 3.4. Dictámenes del Comité de las Regiones y del Comité Económico y Social Europeo. 4. Procedimientos de infracción.

\section{INTRODUCCIÓN}

Esta crónica comprende el periodo que va del 1 de octubre de 2018 al 28 de febrero de 2019. En ella se recoge toda la legislación de las instituciones de la UE aprobada en este lapso de tiempo en materia medioambiental, incluyendo la legislación contra el cambio climático, la protección de la biodiversidad, la legislación sobre contaminantes o la política pesquera entre otros.

Hay que hacer especial mención a la aprobación de un paquete legislativo constituido por un Reglamento centrado en la gobernanza de la Unión en materia de energía y cambio climático y dos Directivas focalizadas en las energías renovables y en la eficiencia energética. Estas normas se enmarcan en el esfuerzo por cumplir los compromisos contraídos con el Acuerdo de París de 2015. De hecho, cabe destacar el gran número de actos legislativos de diferente tipo sobre la contaminación atmosférica que se han aprobado durante este periodo, y en especial los centrados en la reducción de las emisiones de $\mathrm{CO} 2$.

Por último, conviene señalar también la aprobación de varios actos legislativos y actos preparatorios motivados por la perspectiva de la salida de Reino Unido de la Unión.

\section{ACTOS JURÍDICOS EN EL ÁMBITO DE LA POLÍTICA EUROPEA DEL MEDIO AMBIENTE}

\subsection{Actos legislativos}

\section{A) Reglamentos}

Como anunciábamos en la introducción, de todos los reglamentos aprobados durante el periodo analizado destaca el Reglamento (UE) 2018/1999 del Parlamento Europeo y del Consejo, de 11 de diciembre de 2018, sobre la 
gobernanza de la Unión de la Energía y de la Acción por el Clima, y por el que se modifican los Reglamentos (CE) n. ${ }^{\circ} 663 / 2009$ y (CE) n. ${ }^{\circ} 715 / 2009$ del Parlamento Europeo y del Consejo, las Directivas 94/22/CE, 98/70/CE, 2009/31/CE, 2009/73/CE, 2010/31/UE, 2012/27/UE y 2013/30/UE del Parlamento Europeo y del Consejo y las Directivas 2009/119/CE y (UE) 2015/652 del Consejo, y se deroga el Reglamento (UE) n. ${ }^{\circ}$ 525/2013 del Parlamento Europeo y del Consejo. Dando cumplimiento a varias de las propuestas contenidas en el paquete de medidas Energía limpia para todos los europeos propuestas por la Comisión en 2016, este Reglamento renueva el mercado europeo de la energía junto a dos directivas que comentaremos posteriormente, la Directiva (UE) 2018/2002 del Parlamento Europeo y del Consejo de 11 de diciembre de 2018 y la Directiva (UE) 2018/2002 del Parlamento Europeo y del Consejo de 11 de diciembre de 2018.

El elemento de referencia para la reforma de la gobernanza de la energía y de la acción por el clima para las que sienta las bases este Reglamento, es el Acuerdo de París de 2015. En línea con el cumplimiento de los objetivos del Acuerdo, el reglamento de la UE articula los Planes Nacionales de Energía y Clima en cinco dimensiones: descarbonización, eficiencia energética, seguridad energética, mercado interior de la energía y $1+++C$. El presente Reglamento obliga a los Estados miembros a incluir los objetivos comunitarios en materia de energía y acción climática en unos planes nacionales integrados de energía y clima, pues entiende que requiere una acción combinada de los Estados y las instituciones comunitarias. Estos planes nacionales deberán ser elaborados para periodos de diez años a partir de 2021 y en su realización deberán participar los diferentes niveles políticos de cada Estado miembro, partiendo del ámbito local hasta los niveles más altos de decisión. Es relevante aquí el requerimiento de que dichos planes nacionales incluyan una valoración de los hogares en situación de pobreza energética. Como principales novedades, destaca el hecho de que el reglamento de la UE elimina los objetivos nacionales vinculantes y anuncia las medidas para la realización de las contribuciones nacionales de la UE para 2030 en lo que respeta a reducción de las emisiones de gases de efecto invernadero -donde se pretende un reducción del $40 \%$ respecto 1990-, la energía procedente de fuentes renovables y la eficiencia energética, con el fin de "mantener, proteger 
y mejorar la calidad del medio ambiente y de promover una utilización prudente y racional de los recursos naturales".

La regulación del sector del transporte generó durante este periodo cinco reglamentos que cabe analizar desde el punto de vista medioambiental. Respecto a los vehículos terrestres se han regulado en los procesos que estos deben cumplir para su homologación en relación a las emisiones:

- Reglamento (UE) nº. 2018/1832 de la Comisión, de 5 de noviembre de 2018, por el que se modifican la Directiva 2007/46/CE del Parlamento Europeo y del Congreso, el Reglamento (CE) n. ${ }^{\circ} 692 / 2008$ de la Comisión y el Reglamento (UE) 2017/1151 de la Comisión a fin de mejorar los ensayos y los procedimientos de homologación de tipo en lo concerniente a las emisiones aplicables a turismos y vehículos comerciales ligeros, en particular los que se refieren a la conformidad en circulación y a las emisiones en condiciones reales de conducción, y por el que se introducen dispositivos para la monitorización del consumo de combustible y energía eléctrica.

- Reglamento (UE) n. 2019/129 del Parlamento Europeo y del Consejo, de 16 de enero de 2019, por el que se modifica el Reglamento (UE) n. ${ }^{\circ} 168 / 2013$ en lo que se refiere a la aplicación de la fase Euro 5 a la homologación de tipo de los vehículos de dos o tres ruedas y los cuadriciclos.

- Reglamento (UE) n. 2019/318 de la Comisión, de 19 de febrero de 2019, por el que se modifican el Reglamento (UE) 2017/2400 y la Directiva 2007/46/CE del Parlamento Europeo y del Consejo en lo relativo a la determinación de las emisiones de $\mathrm{CO}_{2}$ y el consumo de combustible de los vehículos pesados.

Los dos reglamentos restantes afectan al sector aeronáutico. Estos actualizan la lista de Estados miembros encargados de la regulación del comercio de derechos de emisión de gases de efecto invernadero entre compañías aéreas que realizan ciertas actividades de aviación. Cabe señalar que el primero de estos reglamentos se centra en la adaptación de este ámbito a la salida de la Unión por parte de Reino Unido:

- Reglamento (UE) nº. 2019/225 de la Comisión, de 6 de febrero de 2019, que modifica el Reglamento (CE) $n .^{\circ} 748 / 2009$ en lo que respecta a los operadores 
de aeronaves para los que el Reino Unido se identifica como Estado miembro responsable.

- El Reglamento (UE) n. 2019/226 de la Comisión, de 6 de febrero de 2019, por el que se modifica el Reglamento (CE) n. ${ }^{\circ} 748 / 2009$ de la Comisión sobre la lista de operadores de aeronaves que han realizado una actividad de aviación enumerada en el anexo I de la Directiva 2003/87/CE el 1 de enero de 2006 o a partir de esta fecha.

En el ámbito de la política sobre medio ambiente hay que mencionar, asimismo, la aprobación durante el periodo analizado del Reglamento (UE) 2018/2026 de la Comisión, de 19 de diciembre de 2018, que modifica el anexo IV del Reglamento (CE) n. ${ }^{\circ} 1221 / 2009$ del Parlamento Europeo y del Consejo, relativo a la participación voluntaria de organizaciones en un sistema comunitario de gestión y auditoría medioambientales (EMAS). Siendo el EMAS un sistema de adscripción voluntaria, con este Reglamento se establece la obligación de las organizaciones integradas en él de presentar anualmente una declaración medioambiental actualizada validada por un verificador medioambiental acreditado o autorizado.

En el ámbito de la protección de la biodiversidad se aprobó el Reglamento (UE) $\mathrm{n}^{\circ}$. 2019/220 de la Comisión, de 6 de febrero de 2019, que modifica el Reglamento (CE) n. ${ }^{\circ}$ 865/2006 por el que se establecen disposiciones de aplicación del Reglamento (CE) n. ${ }^{\circ} 338 / 97$ del Consejo, relativo a la protección de especies de la fauna y flora silvestres mediante el control de su comercio. Con objeto de adaptar la legislación de la Unión Europea a las nuevas directrices marcadas por la Convención CITES, este Reglamento establece la prohibición del comercio de marfil proveniente de rinocerontes y elefantes que hayan sido objeto de importación o reexportación, de acuerdo al anexo B del Reglamento (CE) n. 338/97, así como la prohibición de que sean objeto de caza deportiva. También se hacen modificaciones en los códigos descriptivos de las especies de acuerdo con los cambios recientes en dicha Convención.

En el ámbito de la regulación de la producción y uso de sustancias químicas con incidencia en la protección del medioambiente y la salud humana, merece especial consideración el Reglamento (UE) nº. 2018/1881 de la Comisión, de 3 
de diciembre de 2018, por el que se modifica el Reglamento (CE) n. ${ }^{\circ}$ 1907/2006 del Parlamento Europeo y del Consejo, relativo al registro, la evaluación, la autorización y la restricción de las sustancias y mezclas químicas (REACH) en cuanto a sus anexos I, III, VI, VII, VIII, IX, X, XI y XII para tener en cuenta las nanoformas de sustancias. Con este Reglamento se actualiza la regulación REACH de acuerdo a la Comunicación de la Comisión «Segunda revisión de la normativa sobre los nanomateriales».

También se aprobaron tres reglamentos más en este ámbito, aunque de importancia menor:

- Reglamento (UE) ñ. 2018/1480 de la Comisión, de 4 de octubre de 2018, por el que se modifica, a efectos de su adaptación al progreso técnico y científico, el Reglamento (CE) n. ${ }^{\circ}$ 1272/2008 del Parlamento Europeo y del Consejo, sobre clasificación, etiquetado y envasado de sustancias y mezclas, y se corrige el Reglamento (UE) nº. 2017/776 de la Comisión

- Reglamento (UE) n . 2018/1513 de la Comisión, de 10 de octubre de 2018, que modifica, por lo que respecta a determinadas sustancias clasificadas como carcinógenas, mutágenas y tóxicas para la reproducción (CMR), de categoría $1 \mathrm{~A}$ o 1B, el anexo XVII del Reglamento (CE) n. ${ }^{\circ}$ 1907/2006 del Parlamento Europeo y del Consejo, relativo al registro, la evaluación, la autorización y la restricción de las sustancias y mezclas químicas (REACH)

- Reglamento (UE) no. 2018/2005 de la Comisión, de 17 de diciembre de 2018, que modifica el anexo XVII del Reglamento (CE) n. ${ }^{\circ}$ 1907/2006 del Parlamento Europeo y del Consejo, relativo al registro, la evaluación, la autorización y la restricción de las sustancias y mezclas químicas (REACH), por lo que se refiere al ftalato de bis(2-etilhexilo) (DEHP), el ftalato de dibutilo (DBP), el ftalato de bencilo y butilo (BBP) y el ftalato de diisobutilo (DIBP)

La legislación fitosanitaria ha generado diez Reglamentos relativos a la limitación de residuos de ciertas sustancias químicas en productos determinados:

- Reglamento (UE) n. 2019/88 de la Comisión, de 18 de enero de 2019, que modifica el anexo II del Reglamento (CE) n. ${ }^{\circ}$ 396/2005 del Parlamento Europeo y del Consejo por lo que respecta a los límites máximos de residuos de 
acetamiprid en determinados productos.

- Reglamento (UE) n. 2019/89 de la Comisión, de 18 de enero de 2019, que modifica los anexos II, III y V del Reglamento (CE) n. ${ }^{\circ}$ 396/2005 del Parlamento Europeo y del Consejo por lo que respecta a los límites máximos de residuos de bromadiolona, etofenprox, paclobutrazol y penconazol en determinados productos.

- Reglamento (UE) no. 2019/90 de la Comisión, de 18 de enero de 2019, por el que se modifican los anexos II, III y V del Reglamento (CE) n. ${ }^{\circ}$ 396/2005 del Parlamento Europeo y del Consejo por lo que respecta a los límites máximos de residuos de bromuconazol, carboxina, óxido de fenbutaestán, fenpirazamina y piridabeno en determinados productos.

- Reglamento (UE) no. 2019/91 de la Comisión, de 18 de enero de 2019, que modifica los anexos II, III y V del Reglamento (CE) n. ${ }^{\circ}$ 396/2005 del Parlamento Europeo y del Consejo, por lo que respecta a los límites máximos de residuos de buprofezina, diflubenzurón, etoxisulfurón, ioxinil, molinato, picoxistrobina y tepraloxidim en determinados productos.

- Reglamento $n^{\circ}$. (UE) 2019/38 de la Comisión, de 10 de enero de 2019, que modifica los anexos II y V del Reglamento (CE) n. ${ }^{\circ}$ 396/2005 del Parlamento Europeo y del Consejo por lo que respecta a los límites máximos de residuos de iprodiona en determinados productos.

- Reglamento (UE) n . 2019/50 de la Comisión, de 11 de enero de 2019, por el que se modifican los anexos II, III, IV y V del Reglamento (CE) n. ${ }^{\circ} 396 / 2005$ del Parlamento Europeo y del Consejo por lo que respecta a los límites máximos de residuos de clorantraniliprol, clomazona, ciclaniliprol, fenazaquina, fenpicoxamida, fluoxastrobina, lambda-cihalotrina, mepicuat, aceite de cebolla, tiacloprid y valifenalato en determinados productos.

- Reglamento (UE) n. 2019/58 de la Comisión, de 14 de enero de 2019, que modifica los anexos II, III y V del Reglamento (CE) n. ${ }^{\circ}$ 396/2005 del Parlamento Europeo y del Consejo por lo que respecta a los límites máximos de residuos de linurón en determinados productos.

- Reglamento (UE) nº. 2018/1514 de la Comisión, de 10 de octubre de 2018, que 
modifica los anexos II, III y IV del Reglamento (CE) n. ${ }^{\circ}$ 396/2005 del Parlamento Europeo y del Consejo en lo relativo a los límites máximos de residuos de abamectina, acibenzolar-S-metilo, clopiralida, emamectina, fenhexamida, fenpirazamina, fluazifop-P, isofetamida, Pasteuria nishizawae Pn1, talco E553B y tebuconazol en determinados productos.

- Reglamento (UE) n. 2018/1515 de la Comisión, de 10 de octubre de 2018, que modifica los anexos III y V del Reglamento (CE) n. ${ }^{\circ}$ 396/2005 del Parlamento Europeo y del Consejo por lo que respecta a los límites máximos de residuos de difenilamina y oxadixilo en determinados productos.

- Reglamento (UE) nº. 2018/1516 de la Comisión, de 10 de octubre de 2018, que modifica los anexos II y III del Reglamento (CE) n. ${ }^{\circ}$ 396/2005 del Parlamento Europeo y del Consejo por lo que respecta a los límites máximos de residuos de penoxsulam, triflumizol y triflumurón en determinados productos.

En el periodo analizado se hizo una reforma importante de la legislación veterinaria a través de dos Reglamentos: el Reglamento (UE) nº. 2019/4 del Parlamento Europeo y del Consejo, de 11 de diciembre de 2018, relativo a la fabricación, la comercialización y el uso de piensos medicamentosos, por el que se modifica el Reglamento (CE) no. 183/2005 del Parlamento Europeo y del Consejo y se deroga la Directiva 90/167/CEE del Consejo.

Desde el punto de vista medioambiental es especialmente relevante el Reglamento (UE) no. 2019/6 del Parlamento Europeo y del Consejo, de 11 de diciembre de 2018, sobre medicamentos veterinarios y por el que se deroga la Directiva 2001/82/CE. Con la derogación de dicha Directiva, el Reglamento en cuestión pretende mejorar la armonización del mercado único en materia de medicamentos veterinarios, de tal manera que se obliga a hacer controles a nivel de la Unión cuando el país encargado de autorizar la comercialización de un medicamento detecte que puede haber riesgos para el medio ambiente. Asimismo se establece un sistema de control del riesgo medioambiental en dos fases: en la primera se debe evaluar la magnitud de la exposición del medioambiente al producto, mientras que en la segunda se evaluaran los efectos del residuo activo.

En el ámbito de la política pesquera merece especial mención el Reglamento 
(UE) $n^{\circ}$. 2019/124 del Consejo, de 30 de enero de 2019, por el que se establecen, para 2019, las cuotas de pesca para determinadas poblaciones y grupos de poblaciones de peces, aplicables en aguas de la Unión y, en el caso de los buques pesqueros de la Unión, en determinadas aguas no pertenecientes a la Unión. Este reglamento, conforme a la obligación establecida por el Reglamento (UE) $n^{\circ}$. 1380/2013 del Parlamento Europeo y del Consejo, fija las cuotas de pesca por zonas, tipo de pesquería y pabellón de buque de cada Estado miembro para el año entrante de acuerdo a las recomendaciones del Consejo Internacional para la Exploración del Mar (CIEM). Además, se establecen mecanismos para la progresiva reducción de capturas accesorias de especies la situación biológica de las cuales se podría ver en riesgo según la CIEM.

En la misma línea, aunque antes de cerrar el año 2018, el Consejo aprobó tres reglamentos con las mismas funciones que el reglamento anteriormente comentado, pero para las aguas del Mar Báltico, el Mar Negro y las aguas profundas:

- Reglamento (UE) n. 2018/1628 del Consejo, de 30 de octubre de 2018, por el que se establecen, para 2019, las cuotas de pesca de determinadas poblaciones y grupos de poblaciones de peces en el Mar Báltico y por el que se modifica el Reglamento (UE) n. 2018/120 en lo que respecta a determinadas cuotas de pesca en otras aguas.

- Reglamento (UE) n. 2018/2025 del Consejo, de 17 de diciembre de 2018, por el que se fijan para los buques pesqueros de la Unión las cuotas de pesca en 2019 y 2020 de determinadas poblaciones de peces de aguas profundas.

- Reglamento (UE) n. 2018/2058 del Consejo, de 17 de diciembre de 2018, por el que se establecen, para 2019, las cuotas de pesca aplicables a determinadas poblaciones y grupos de poblaciones de peces en el Mar Negro.

También cabe mencionar el Reglamento (UE) nº. 2019/440 del Consejo, de 29 de noviembre de 2018 , relativo al reparto de las cuotas de pesca en virtud del Acuerdo de colaboración de pesca sostenible entre la Unión Europea y el Reino de Marruecos y de su Protocolo de aplicación, con el que se aprobaba el resultado de las negociaciones llevadas a cabo por la Comisión en nombre del Consejo con Marruecos y en el que se establecen los límites de pesca para un 
periodo de cuatro años.

Así mismo la Comisión ha aprobado, en el periodo de tiempo analizado, 31 Reglamentos relativos a la prohibición de pesca para ciertas zonas en función del tipo de pesquería y del pabellón del buque pesquero:

- Reglamento (UE) nº. 2018/1677 de la Comisión, de 5 de noviembre de 2018, por el que se prohíbe la pesca de lenguado europeo en las zonas $7 \mathrm{~h}, 7 \mathrm{j}$ y $7 \mathrm{k}$ por parte de buques que enarbolen el pabellón de Bélgica.

- Reglamento (UE) no. 2018/1678 de la Comisión, de 5 de noviembre de 2018, por el que se prohíbe la pesca de eglefino en las zonas $7 \mathrm{~b}-\mathrm{k}, 8,9$ y 10 y en aguas de la Unión de la zona 34.1.1 del CPACO por parte de buques que enarbolen el pabellón de Bélgica.

- Reglamento (UE) no. 2018/1679 de la Comisión, de 5 de noviembre de 2018, por el que se prohíbe la pesca de jurel chileno en la zona de la Convención SPRFMO por parte de buques que enarbolen el pabellón de Lituania.

- Reglamento (UE) no. 2018/1680 de la Comisión, de 5 de noviembre de 2018, por el que se prohíbe la pesca de solla en las zonas $7 \mathrm{~h}, 7 \mathrm{j}$ y $7 \mathrm{k}$ por parte de los buques que enarbolan pabellón de Bélgica.

- Reglamento (UE) nº. 2018/1681 de la Comisión, de 5 de noviembre de 2018, por el que se prohíbe la pesca de jurel chileno en la zona de la Convención SPRFMO por parte de buques que enarbolen el pabellón de los Países Bajos.

- Reglamento (UE) no. 2018/1682 de la Comisión, de 5 de noviembre de 2018, por el que se prohíbe la pesca de jurel chileno en la zona de la Convención de la SPRFMO a los buques que enarbolan el pabellón de Polonia.

- Reglamento (UE) no. 2018/1683 de la Comisión, de 5 de noviembre de 2018, por el que se prohíbe la pesca de jurel chileno en la zona de la Convención SPRFMO por parte de los buques que enarbolan pabellón de Alemania.

- Reglamento (UE) no. 2018/1833 de la Comisión, de 19 de noviembre de 2018, por el que se prohíbe la pesca de maruca en aguas de la Unión de la zona 3a a los buques que enarbolan pabellón de Dinamarca.

- Reglamento (UE) nº. 2018/1834 de la Comisión, de 19 de noviembre de 2018, 
por el que se prohíbe la pesca de raya mosaico en aguas de la Unión de la zona 8 a los buques que enarbolan pabellón de España.

- Reglamento (UE) nº. 2018/1835 de la Comisión, de 19 de noviembre de 2018, por el que se prohíbe la pesca de raya mosaico en aguas de la Unión de la zona 9 a los buques que enarbolan pabellón de España.

- Reglamento (UE) n. 2018/1836 de la Comisión, de 19 de noviembre de 2018, por el que se prohíbe la pesca de carbonero en la zona 6 y en aguas de la Unión y aguas internacionales de las zonas $5 \mathrm{~b}, 12$ y 14 a los buques que enarbolan pabellón de España.

- Reglamento (UE) n. 2018/1894 de la Comisión, de 30 de noviembre de 2018, por el que se prohíbe la pesca de cigala en las zonas $8 \mathrm{a}, 8 \mathrm{~b}, 8 \mathrm{~d}$ y $8 \mathrm{e}$ por parte de los buques que enarbolan pabellón de Bélgica.

- Reglamento (UE) n. 2018/1895 de la Comisión, de 30 de noviembre de 2018, por el que se prohíbe la pesca de gallo en las zonas $8 a, 8 b, 8 d$ y $8 e$ por parte de los buques que enarbolan pabellón de Bélgica.

- Reglamento (UE) n. 2018/1896 de la Comisión, de 30 de noviembre de 2018, por el que se prohíbe la pesca de merluza en las zonas $8 a, 8 b, 8 d$ y $8 e$ por parte de los buques que enarbolan pabellón de Bélgica.

- Reglamento (UE) n. 2018/1897 de la Comisión, de 30 de noviembre de 2018, por el que se prohíbe la pesca de rayas en aguas de la Unión de las zonas 8 y 9 por parte de los buques que enarbolan pabellón de Bélgica.

- Reglamento (UE) nº 2018/1898 de la Comisión, de 30 de noviembre de 2018, por el que se prohíbe la pesca de solla en las zonas 8,9 y 10, y en aguas de la Unión del CPACO 34.1.1, por parte de los buques que enarbolan pabellón de Bélgica.

- Reglamento (UE) n. 2018/1899 de la Comisión, de 30 de noviembre de 2018, por el que se prohíbe la pesca de merlán en la zona 8 por parte de los buques que enarbolan pabellón de Bélgica.

- Reglamento (UE) n . 2018/1900 de la Comisión, de 30 de noviembre de 2018, por el que se prohíbe la pesca de bacalao en las subdivisiones 22-24 por parte 
de los buques que enarbolan pabellón de Polonia.

- Reglamento (UE) n. 2018/1901 de la Comisión, de 30 de noviembre de 2018, por el que se prohíbe la pesca de rape en las zonas $8 \mathrm{a}, 8 \mathrm{~b}, 8 \mathrm{~d}$ y $8 \mathrm{e}$ por parte de los buques que enarbolan pabellón de Bélgica.

- Reglamento (UE) n. 2018/1902 de la Comisión, de 30 de noviembre de 2018, por el que se prohíbe la pesca de lenguado europeo en las zonas $8 \mathrm{a}$ y $8 \mathrm{~b}$ por parte de los buques que enarbolan pabellón de Bélgica.

- Reglamento (UE) n. 2018/1949 de la Comisión, de 4 de diciembre de 2018, por el que se prohíbe la pesca de patudo en el Océano Atlántico por parte de los buques que enarbolan pabellón de España.

- Reglamento (UE) no. 2018/1950 de la Comisión, de 4 de diciembre de 2018, por el que se prohíbe la pesca de eglefino en aguas de la Unión y aguas internacionales de las zonas $5 \mathrm{~b}$ y $6 a$ por parte de los buques que enarbolan pabellón de España.

- Reglamento (UE) nº. 2018/1951 de la Comisión, de 4 de diciembre de 2018, por el que se prohíbe la pesca de brosmio en aguas de la Unión y aguas internacionales de las zonas 5,6 y 7 por parte de los buques que enarbolan pabellón de España.

- Reglamento (UE) nº. 2018/1952 de la Comisión, de 4 de diciembre de 2018, por el que se prohíbe la pesca de alfonsinos en aguas de la Unión y aguas internacionales de las zonas III, IV, V, VI, VII, VIII, IX, X, XII y XIV por parte de los buques que enarbolan pabellón de España.

- Reglamento (UE) nº. 2018/1953 de la Comisión, de 4 de diciembre de 2018, por el que se prohíbe la pesca de solla en las zonas $7 \mathrm{~h}, 7 \mathrm{j}$ y $7 \mathrm{k}$ por parte de los buques que enarbolan pabellón de Francia.

- Reglamento (UE) nº. 2018/1954 de la Comisión, de 4 de diciembre de 2018, por el que se prohíbe la pesca de bacalao en la zona NAFO $3 \mathrm{M}$ a los buques que enarbolan pabellón de un Estado miembro de la Unión Europea.

- Reglamento (UE) n. 2018/1955 de la Comisión, de 4 de diciembre de 2018, por el que se prohíbe a los buques que enarbolan pabellón de Portugal la pesca 
de raya mosaico en aguas de la Unión de la zona 9.

- Reglamento (UE) n . 2018/2037 de la Comisión, de 17 de diciembre de 2018, por el que se prohíbe la pesca de arenque en aguas de la Unión y aguas internacionales de las zonas $5 b, 6 b$ y $6 a \mathrm{~N}$ por parte de los buques que enarbolan pabellón de Francia.

- Reglamento (UE) no. 2018/2038 de la Comisión, de 17 de diciembre de 2018, por el que se prohíbe la pesca de carbonero en aguas de Noruega de las zonas 1 y 2 por parte de los buques que enarbolan pabellón de Francia.

- Reglamento (UE) no. 2018/2039 de la Comisión, de 17 de diciembre de 2018, por el que se prohíbe la pesca de maruca en aguas de la Unión y aguas internacionales de las zonas 1 y 2 por parte de los buques que enarbolan pabellón de Francia.

- Reglamento (UE) n . 2018/2040 de la Comisión, de 17 de diciembre de 2018, por el que se prohíbe la pesca de atún blanco del norte en el océano Atlántico, al norte del paralelo $5^{\circ} \mathrm{N}$, por parte de los buques que enarbolan pabellón de Francia.

\section{b) Directivas}

Anteriormente ya hemos mencionado la complementariedad del Reglamento (UE) $n^{\circ}$. 2018/1999 del Parlamento Europeo y del Consejo, de 11 de diciembre de 2018, sobre la gobernanza de la Unión de la Energía y de la Acción por el Clima, y por el que se modifican los Reglamentos (CE) n. ${ }^{\circ} 663 / 2009$ y (CE) n. ${ }^{\circ}$ 715/2009 del Parlamento Europeo y del Consejo, las Directivas 94/22/CE, 98/70/CE, 2009/31/CE, 2009/73/CE, 2010/31/UE, 2012/27/UE y 2013/30/UE del Parlamento Europeo y del Consejo y las Directivas 2009/119/CE y (UE) 2015/652 del Consejo, y se deroga el Reglamento (UE) n. ${ }^{\circ}$ 525/2013 del Parlamento Europeo y del Consejo con tres nuevas directivas.

La Directiva 2018/2001 del Parlamento Europeo y del Consejo, de 11 de diciembre de 2018, relativa al fomento del uso de energía procedente de fuentes renovables, cuya fecha de transposición es el 31 de diciembre de 2021, se centra en la consecución de los mismos objetivos del Reglamento antes mencionado, el Acuerdo de París y los objetivos de la Unión para 2030 en el ámbito de las 
energías renovables. Pretende establecer un marco común para su fomento, así como establecer normas relativas a las ayudas a la producción de energía eléctrica procedente de fuentes renovables y a la producción y uso de dicha energía, incluyendo el autoconsumo. Merece especial mención la fijación de único objetivo vinculante para la UE del $32 \%$ de uso de energía renovable para 2030 , sin ningún objetivo nacional vinculante para los Estados miembros (si bien los objetivos nacionales establecidos por la Directiva 2009/28/CE siguen siendo relevantes como niveles mínimos nacionales). Las contribuciones nacionales deben también contemplar ahora el aumento del uso de las energías renovables en el transporte (proveedores de combustibles: al menos el $14 \%$ procedente de fuentes renovables), además de la eliminación progresiva hasta 2030 de los biocombustibles convencionales con alto riesgo de cambio indirecto en el uso de la tierra.

La directiva prevé asimismo los mecanismos de apoyo basados en el mercado para proyectos de energía renovable (primas de mercado, ayudas públicas y condiciones de las licitaciones), suprime las reglas de prioridad en el acceso a la red para las energías renovables de la Directiva 2009/28/CE, con lo que ofrece mayor flexibilidad para los operadores económicos y ordena las "garantías de origen" que se otorgarán a las energías renovables y, opcionalmente, también a proyectos de energía no renovable. Destacan, además, las medidas para facilitar el autoconsumo y la participación de los consumidores y de las comunidades de consumidores en el despliegue de las energías renovables (posibilidad de generar, almacenar y consumir energía renovable, así como vender el exceso de producción y participar en el esquema de soporte aplicable).

La Directiva 2018/2002 del Parlamento Europeo y del Consejo, de 11 de diciembre de 2018, por la que se modifica la Directiva 2012/27/UE relativa a la eficiencia energética, cuya fecha de transposición es el 25 de junio de 2020, también es un medio de realización de los compromisos de la UE asumidos en el Acuerdo de París, aunque ahora desde la perspectiva de la eficiencia energética. Se inspira en la comunicación de la Comisión del 25 de febrero de 2015 titulada "Estrategia Marco para una Unión de la Energía resiliente con una política climática prospectiva", donde se fija la moderación de la demanda de energía como una de las cinco dimensiones de la Estrategia de la Unión en 
materia de energía. Para ese fin la directiva en cuestión aumenta en 12,5 puntos el porcentaje de ahorro de energía que la directiva de 2009 estableció en su momento, llegando ahora al 32,5\%. La nueva directiva extiende la obligación anual de ahorros más allá del año 2020 y requiere de los Estados miembros la adopción de normas nacionales transparentes y accesibles al público en materia de reparto de los costes del consumo. Entre las medidas para cumplir tal objetivo se encuentran, por ejemplo, la regulación de las ayudas públicas dirigidas a fomentar la eficiencia energética de edificios o la obligación de instalar contadores de lectura remota antes de 2020.

\section{c) Decisiones}

Durante el período de tiempo analizado la Comisión Europea ha adoptado tres Decisiones sobre la etiqueta ecológica de la UE. La primera afecta al período de validez de los criterios ecológicos establecidos para la concesión de dicha etiqueta para los productos absorbentes de higiene personal, papel impreso, colchones y productos cosméticos. La segunda, por su parte, afecta a los productos lubricantes y la tercera al papel tisú:

- Decisión (UE) 2018/1590 de la Comisión, de 19 de octubre de 2018, por la que se modifican las Decisiones 2012/481/UE, 2014/391/UE, 2014/763/UE y 2014/893/UE en lo que respecta al período de validez de los criterios ecológicos para la concesión de la etiqueta ecológica de la UE a determinados productos, así como de los correspondientes requisitos de evaluación y verificación [notificada con el número C (2018) 6805].

- Decisión (UE) 2018/1702 de la Comisión, de 8 de noviembre de 2018, por la que se establecen los criterios de la etiqueta ecológica de la UE para lubricantes [notificada con el número C (2018) 7125].

- Decisión (UE) 2019/70 de la Comisión, de 11 de enero de 2019, por la que se establecen los criterios de la etiqueta ecológica de la UE para el papel gráfico y los criterios de la etiqueta ecológica de la UE para el papel tisú y los productos de papel tisú [notificada con el número C (2019) 3]

Junto al Reglamento (UE) n. 2018/2026 de la Comisión, de 19 de diciembre de 2018 que mencionamos más arriba y con objeto de dar cumplimiento a la 
obligación impuesta a la Comisión mediante el Reglamento (CE) n. 1221/2009, se han aprobado tres Decisiones como documentos de referencia sectoriales a partir de organizaciones integradas voluntariamente en el sistema comunitario de gestión y auditoría medioambientales (EMAS). Concretamente, se trata del sector de la administración pública, el sector de la fabricación de automóviles y el sector de la fabricación de aparatos eléctricos:

- Decisión (UE) 2019/61 de la Comisión, de 19 de diciembre de 2018, relativa al documento de referencia sectorial sobre las mejores prácticas de gestión ambiental, los indicadores sectoriales de comportamiento ambiental y los parámetros comparativos de excelencia para el sector de la administración pública en el marco del Reglamento (CE) n. ${ }^{\circ} 1221 / 2009$, relativo a la participación voluntaria de organizaciones en un sistema comunitario de gestión y auditoría medioambientales (EMAS).

- Decisión (UE) 2019/62 de la Comisión, de 19 de diciembre de 2018, relativa al documento de referencia sectorial sobre las mejores prácticas de gestión medioambiental, los indicadores sectoriales de comportamiento medioambiental y los parámetros comparativos de excelencia para el sector de la fabricación de automóviles en el marco del Reglamento (CE) n. 1221/2009, relativo a la participación voluntaria de organizaciones en un sistema comunitario de gestión y auditoría medioambientales (EMAS).

- Decisión (UE) 2019/63 de la Comisión, de 19 de diciembre de 2018, relativa al documento de referencia sectorial sobre las mejores prácticas de gestión medioambiental, los indicadores sectoriales de comportamiento medioambiental y los parámetros comparativos de excelencia para el sector de la fabricación de aparatos eléctricos y electrónicos en el marco del Reglamento (CE) n. ${ }^{\circ}$ 1221/2009 del Parlamento Europeo y del Consejo, relativo a la participación voluntaria de organizaciones en un sistema comunitario de gestión y auditoría medioambientales (EMAS).

\subsection{Actos delegados}

\section{a) Reglamentos delegados}

En el ámbito de los derechos de emisión de gases se aprobaron, durante este 
periodo, cuatro Reglamentos delegados. Como con la Directiva (UE) 2018/410 del Parlamento Europeo y del Consejo se modificaron de forma sustancial las normas transitorias de la Unión para la armonización de la asignación gratuita de derechos de emisión, fue necesario adoptar, por motivos de claridad, el Reglamento Delegado (UE) no. 2019/331 de la Comisión, de 19 de diciembre de 2018, por el que se determinan las normas transitorias de la Unión para la armonización de la asignación gratuita de derechos de emisión con arreglo al artículo 10 bis de la Directiva 2003/87/CE del Parlamento Europeo y del Consejo.

Los otros tres Reglamentos delegados son, sin mayor comentario:

- Reglamento Delegado (UE) n $n^{\circ}$. 2019/7 de la Comisión, de 30 de octubre de 2018, por el que se modifica el Reglamento (UE) n. ${ }^{\circ}$ 1031/2010 en lo que respecta a la subasta de 50 millones de derechos de emisión sin asignar de la reserva de estabilidad del mercado para el fondo de innovación y con objeto de registrar una plataforma de subastas que va a designar Alemania.

- Reglamento Delegado (UE) n. 2019/248 de la Comisión, de 13 de noviembre de 2018, que corrige el Reglamento (UE) n. ${ }^{\circ}$ 63/2011, por el que se establecen normas detalladas para la solicitud de una excepción a los objetivos específicos de emisión de $\mathrm{CO}_{2}$, de conformidad con el artículo 11 del Reglamento (CE) n. ${ }^{\circ}$ 443/2009 del Parlamento Europeo y del Consejo.

- Reglamento Delegado (UE) nº. 2019/401 de la Comisión, de 19 de diciembre de 2018, que modifica el Reglamento (UE) n. ${ }^{\circ} 389 / 2013$ por el que se establece el Registro de la Unión.

Por otro lado, la política pesquera ha generado cuatro Reglamentos delegados que regulan el descarte de peces para el período 2019-2021 de acuerdo al Reglamento (UE) nº. 1380/2013, el cual obliga a una reducción progresiva de los descartes de especies sujetas a límites de captura mediante su desembarco:

- Reglamento Delegado (UE) no. 2018/2033 de la Comisión, de 18 de octubre de 2018, por el que se establece un plan de descartes para determinadas pesquerías demersales en aguas suroccidentales para el período 2019-2021.

- Reglamento Delegado (UE) n n. 2018/2034 de la Comisión, de 18 de octubre de 2018, por el que se establece un plan de descartes para determinadas 
pesquerías demersales en aguas noroccidentales para el período 2019-2021.

- Reglamento Delegado (UE) n. 2018/2035 de la Comisión, de 18 de octubre de 2018, por el que se detallan las disposiciones de aplicación de la obligación de desembarque en determinadas pesquerías demersales del mar del Norte para el período 2019-2021.

- Reglamento Delegado (UE) n. 2018/2036 de la Comisión, de 18 de octubre de 2018, que modifica el Reglamento Delegado (UE) 2017/86, por el que se establece un plan de descartes para determinadas pesquerías demersales en el mar Mediterráneo.

Finalmente, en materia de importación y exportación de productos químicos peligrosos se aprobó el Reglamento Delegado (UE) n. 2019/330 de la Comisión, de 11 de diciembre de 2018, por el que se modifican los anexos I y $\mathrm{V}$ del Reglamento (UE) n. ${ }^{\circ}$ 649/2012 del Parlamento Europeo y del Consejo, relativo a la exportación e importación de productos químicos peligrosos. Con éste se actualiza la lista de productos químicos peligrosos permitidos en el comercio exterior a partir de las últimas decisiones técnicas.

\section{b) Directivas delegadas}

Durante el período analizado se han aprobado diez directivas delegadas relevantes para el medioambiente, que realizan una actualización de la exención a la prohibición para ciertos materiales peligrosos prohibidos para la fabricación de aparatos eléctricos y electrónicos establecida en la Directiva 2011/65/UE:

- Directiva Delegada (UE) 2019/169 de la Comisión, de 16 de noviembre de 2018, por la que se modifica, para adaptarlo al progreso científico y técnico, el anexo III de la Directiva 2011/65/UE del Parlamento Europeo y del Consejo en cuanto a una exención relativa al plomo en cerámica dieléctrica de determinados condensadores.

- Directiva Delegada (UE) 2019/170 de la Comisión, de 16 de noviembre de 2018, por la que se modifica, para adaptarlo al progreso científico y técnico, el anexo III de la Directiva 2011/65/UE del Parlamento Europeo y del Consejo en cuanto a una exención relativa al plomo en materiales cerámicos dieléctricos $\mathrm{PZT}$ de determinados condensadores. 
- Directiva Delegada (UE) 2019/171 de la Comisión, de 16 de noviembre de 2018, por la que se modifica, para adaptarlo al progreso científico y técnico, el anexo III de la Directiva 2011/65/UE del Parlamento Europeo y del Consejo en cuanto a una exención relativa al cadmio y sus compuestos en contactos eléctricos.

- Directiva Delegada (UE) 2019/172 de la Comisión, de 16 de noviembre de 2018, por la que se modifica, para adaptarlo al progreso científico y técnico, el anexo III de la Directiva 2011/65/UE del Parlamento Europeo y del Consejo en cuanto a una exención relativa al plomo en pastas de soldadura diseñadas para crear una conexión eléctrica viable entre el cubo de semiconductor y el portador en cápsulas de circuito integrado flip-chip.

- Directiva Delegada (UE) 2019/173 de la Comisión, de 16 de noviembre de 2018, por la que se modifica, para adaptarlo al progreso científico y técnico, el anexo III de la Directiva 2011/65/UE del Parlamento Europeo y del Consejo por lo que respecta a una exención relativa al plomo y al cadmio en tintas de impresión para la aplicación de esmaltes en vidrios.

- Directiva Delegada (UE) 2019/174 de la Comisión, de 16 de noviembre de 2018, por la que se modifica, para adaptarlo al progreso científico y técnico, el anexo III de la Directiva 2011/65/UE del Parlamento Europeo y del Consejo en cuanto a una exención relativa al plomo en vidrio cristal conforme a la definición de la Directiva 69/493/CEE.

- Directiva Delegada (UE) 2019/175 de la Comisión, de 16 de noviembre de 2018, por la que se modifica, para adaptarlo al progreso científico y técnico, el anexo III de la Directiva 2011/65/UE del Parlamento Europeo y del Consejo en cuanto a una exención relativa al plomo en la frita de sellado utilizada para hacer montajes de ventana para determinados tubos láser.

- Directiva Delegada (UE) 2019/176 de la Comisión, de 16 de noviembre de 2018, por la que se modifica, para adaptarlo al progreso científico y técnico, el anexo III de la Directiva 2011/65/UE del Parlamento Europeo y del Consejo en cuanto a una exención relativa al plomo de la capa de revestimiento de determinados diodos.

- Directiva Delegada (UE) 2019/177 de la Comisión, de 16 de noviembre de 2018, 
por la que se modifica, para adaptarlo al progreso científico y técnico, el anexo III de la Directiva 2011/65/UE del Parlamento Europeo y del Consejo en cuanto a una exención relativa al plomo empleado como activador en el polvo fluorescente de las lámparas de descarga utilizadas como lámparas de bronceado que contengan fósforos.

- Directiva Delegada (UE) 2019/178 de la Comisión, de 16 de noviembre de 2018, por la que se modifica, para adaptarlo al progreso científico y técnico, el anexo III de la Directiva 2011/65/UE del Parlamento Europeo y del Consejo en lo relativo a una exención para el plomo en cojinetes y pistones utilizados en determinados equipos no viales de uso profesional.

\subsection{Actos de ejecución}

a) Reglamentos de ejecución

En el ámbito de la reducción de emisiones de $\mathrm{CO}_{2}$, la Comisión aprobó dos Reglamentos delegados con el fin de aclarar criterios y hacer comparables las mediciones de emisiones de vehículos comerciales ligeros hechas de acuerdo al Reglamento de Ejecución (UE) nº. 2017/1152 con las anteriores:

- Reglamento de Ejecución (UE) n. 2018/2042 de la Comisión, de 18 de diciembre de 2018, por el que se modifica el Reglamento de Ejecución (UE) nº. 2017/1152 con el fin de aclarar las condiciones de los ensayos WLTP y garantizar el seguimiento de los datos relativos a la homologación de tipo.

- Reglamento de Ejecución (UE) nº 2018/2043 de la Comisión, de 18 de diciembre de 2018, por el que se modifica el Reglamento de Ejecución (UE) nº. 2017/1153 con el fin de aclarar las condiciones de los ensayos WLTP y garantizar el seguimiento de los datos relativos a la homologación de tipo.

También en el ámbito de las emisiones de $\mathrm{CO}_{2}$, se han aprobado otros dos importantes reglamentos delegados para el sector de la aviación. En primer lugar, el Reglamento de Ejecución (UE) nº. 2018/2066 de la Comisión, de 19 de diciembre de 2018, sobre el seguimiento y la notificación de las emisiones de gases de efecto invernadero en aplicación de la Directiva 2003/87/CE del Parlamento Europeo y del Consejo y por el que se modifica el Reglamento (UE) n. ${ }^{\circ} 601 / 2012$ de la Comisión. Este reglamento establece el sistema de medición 
y notificación de emisiones de gases de efecto invernadero que se ha de aplicar al comercio de derechos de emisión de la UE a partir del 1 de enero de 2021.

En segundo lugar, se aprobó el Reglamento de Ejecución (UE) nº 2018/2067 de la Comisión, de 19 de diciembre de 2018, relativo a la verificación de los datos y a la acreditación de los verificadores de conformidad con la Directiva 2003/87/CE del Parlamento Europeo y del Consejo. De forma complementaria al Reglamento de Ejecución (UE) nº. 2018/2066 mencionado arriba, el presente Reglamento de ejecución regula el proceso de certificación de los verificadores encargados de hacer el control sobre los informes de emisiones de gases de efecto invernadero por parte de los operadores del sector de la aviación a partir del 1 de enero de 2019. También regula el reconocimiento mutuo de verificadores entre las agencias nacionales encargadas de su acreditación.

También relativos al sector del transporte aéreo, cabe mencionar dos Reglamentos de ejecución que, aunque de menor interés desde el punto de vista medioambiental, también incluyen esta perspectiva para el diseño de la red europea de rutas aéreas y la evaluación del rendimiento y de tarificación de los servicios de navegación aérea:

- Reglamento de Ejecución (UE) n. 2019/123 de la Comisión, de 24 de enero de 2019, por el que se establecen disposiciones de aplicación de las funciones de la red de gestión del tránsito aéreo (ATM) y por el que se deroga el Reglamento (UE) n. ${ }^{\circ} 677 / 2011$.

- Reglamento de Ejecución (UE) n. 2019/317 de la Comisión, de 11 de febrero de 2019, por el que se establece un sistema de evaluación del rendimiento y de tarificación en el cielo único europeo y se derogan los Reglamentos de Ejecución (UE) n. ${ }^{\circ} 390 / 2013$ y (UE) n. ${ }^{\circ} 391 / 2013$.

La eventual salida del Reino Unido de la Unión Europea ha conllevado la adopción, por parte de la Comisión, de una serie de medidas para mantener un registro diferenciado de los hidrofluorocarburos comercializados en la Unión, a parte de los comercializados en Reino Unido y poder llevar a cabo así la reducción de éstos: Reglamento de Ejecución (UE) nº 2018/1992 de la Comisión, de 14 de diciembre de 2018, por el que se modifica el Reglamento de Ejecución (UE) n. ${ }^{\circ} 1191 / 2014$ en lo relativo a la notificación de los datos a que 
hace referencia el artículo 19 del Reglamento (UE) n. ${ }^{\circ}$ 517/2014 con relación a los hidrofluorocarburos comercializados en el Reino Unido y en la Unión de 27 Estados miembros.

La regulación de los productos fitosanitarios ha generado ocho Reglamentos de ejecución durante el período analizado. Merece especial mención el Reglamento de Ejecución (UE) nº 2019/66 de la Comisión, de 16 de enero de 2019, relativo a las normas sobre disposiciones prácticas uniformes para la realización de controles oficiales de los vegetales, los productos vegetales y otros objetos destinados a comprobar el cumplimiento de las normas de la Unión relativas a las medidas de protección contra las plagas de los vegetales aplicables a dichas mercancías. Establece como norma general la obligación de realizar controles anuales como mínimo a las instalaciones de los operadores autorizados a expedir pasaportes fitosanitarios de acuerdo con el artículo 84, apartado 1, del Reglamento (UE) n. 2016/2031.

Los otros siete Reglamentos de ejecución a los que hacíamos referencia son los siguientes:

- Reglamento de Ejecución (UE) n. 2018/1495 de la Comisión, de 8 de octubre de 2018, por el que se modifica el Reglamento de Ejecución (UE) n. ${ }^{\circ}$ 540/2011 en lo que respecta a las condiciones de aprobación de la sustancia activa malatión.

- Reglamento de Ejecución (UE) nº 2018/1660 de la Comisión, de 7 de noviembre de 2018, por el que se imponen condiciones especiales a la importación de determinados alimentos de origen no animal procedentes de determinados terceros países debido a los riesgos de contaminación por residuos de plaguicidas, por el que se modifica el Reglamento (CE) n. ${ }^{\circ} 669 / 2009$ y por el que se deroga el Reglamento de Ejecución (UE) n. ${ }^{\circ}$ 885/2014.

- Reglamento de Ejecución (UE) n. 2018/1914 de la Comisión, de 6 de diciembre de 2018, relativo a la no renovación de la aprobación de la sustancia activa quinoxifeno con arreglo a lo dispuesto en el Reglamento (CE) n. ${ }^{\circ} 1107 / 2009$ del Parlamento Europeo y del Consejo, relativo a la comercialización de productos fitosanitarios, y por el que se modifica el Reglamento de Ejecución (UE) n. ${ }^{\circ}$ 540/2011 de la Comisión. 
- Reglamento de Ejecución (UE) n. 2018/1916 de la Comisión, de 6 de diciembre de 2018, que modifica el Reglamento de Ejecución (UE) n. ${ }^{\circ}$ 540/2011 por lo que respecta a la ampliación del período de aprobación de la sustancia activa bispiribaco.

- Reglamento de Ejecución (UE) n. 2018/1865 de la Comisión, de 28 de noviembre de 2018, relativo a la no renovación de la aprobación de la sustancia activa propiconazol, de conformidad con el Reglamento (CE) n. ${ }^{\circ} 1107 / 2009$ del Parlamento Europeo y del Consejo, relativo a la comercialización de productos fitosanitarios, y por el que se modifica el Reglamento de Ejecución (UE) n. ${ }^{\circ}$ 540/2011 de la Comisión.

- Reglamento de Ejecución (UE) n. 2018/1981 de la Comisión, de 13 de diciembre de 2018, por el que se renueva la aprobación de los compuestos de cobre como sustancias activas candidatas a la sustitución de conformidad con el Reglamento (CE) n. ${ }^{\circ}$ 1107/2009 del Parlamento Europeo y del Consejo, relativo a la comercialización de productos fitosanitarios, y se modifica el anexo del Reglamento de Ejecución (UE) n. ${ }^{\circ}$ 540/2011 de la Comisión.

- Reglamento de Ejecución (UE) n. 2019/291 de la Comisión, de 19 de febrero de 2019, por el que se modifica el Reglamento de Ejecución (UE) n. ${ }^{\circ}$ 540/2011 en lo que se refiere a la prórroga de los períodos de aprobación de las sustancias activas 1-naftilacetamida, ácido 1-naftilacético, acrinatrina, azoxistrobina, fluazifop-P, fluroxipir, imazalilo, cresoxim-metilo, oxifluorfeno, procloraz, prohexadiona, espiroxamina, teflutrina y terbutilazina.

Se aprobó también un Reglamento de ejecución en el ámbito de la legislación veterinaria: Reglamento de Ejecución (UE)nº. 2018/1882 de la Comisión, de 3 de diciembre de 2018, relativo a la aplicación de determinadas normas de prevención y control a categorías de enfermedades enumeradas en la lista y por el que se establece una lista de especies y grupos de especies que suponen un riesgo considerable para la propagación de dichas enfermedades de la lista. La Comisión junto a la Autoridad Europea de Seguridad Alimentaria (EFSA) realizaron una evaluación sistemática de estas enfermedades y determinaron que podían ser dañinas para la salud humana, pero también para el medio ambiente y la biodiversidad. 
En el ámbito de la producción de productos electrónicos se aprobó el Reglamento de Ejecución (UE) n. 2019/290 de la Comisión, de 19 de febrero de 2019, por el que se establece el formato para la inscripción en el registro y para la presentación de informes de los productores de aparatos eléctricos y electrónicos al registro. Esta norma pretende armonizar la inscripción de dichos aparatos a partir del 1 de enero de 2020 y aliviar la carga administrativa que dichos trámites suponen para los fabricantes.

Por último, en el ámbito de la política pesquera se aprobó el Reglamento de Ejecución (UE) n. 2018/1585 de la Comisión, de 22 de octubre de 2018, por el que se establece una excepción respecto a lo dispuesto en el Reglamento (CE) n. ${ }^{\circ} 1967 / 2006$ del Consejo en lo concerniente a la distancia mínima de la costa y la profundidad marina mínima para la pesca con redes de cerco con jareta en aguas territoriales de Croacia.

\section{b) Decisiones de ejecución}

Este período ha sido especialmente prolijo por lo que respecta a Decisiones de ejecución en el ámbito de la legislación para la reducción de las emisiones de contaminantes atmosféricos. Tres de ellas afectan a los sistemas de control y notificación de las emisiones de dichos contaminantes por parte de los Estados miembros:

- Decisión de Ejecución (UE) 2018/1522 de la Comisión, de 11 de octubre de 2018, por la que se establece un formato común para los programas nacionales de control de la contaminación atmosférica en el marco de la Directiva (UE) 2016/2284 del Parlamento Europeo y del Consejo, relativa a la reducción de las emisiones nacionales de determinados contaminantes atmosféricos [notificada con el número C (2018) 6549].

- Decisión de Ejecución (UE) 2018/1855 de la Comisión, de 27 de noviembre de 2018, relativa a las emisiones de gases de efecto invernadero contempladas en la Decisión n. ${ }^{\circ}$ 406/2009/CE del Parlamento Europeo y del Consejo correspondientes a cada Estado miembro en 2016.

- Decisión de Ejecución (UE) 2018/2023 de la Comisión, de 17 de diciembre de 2018, relativa a la modificación de la Decisión de Ejecución (UE) 2017/1984 de 
la Comisión, por la que se determinan valores de referencia, de conformidad con el Reglamento (UE) n. ${ }^{\circ}$ 517/2014 del Parlamento Europeo y del Consejo, sobre los gases fluorados de efecto invernadero, por lo que respecta a los valores de referencia para el período comprendido entre el 30 de marzo de 2019 y el 31 de diciembre de 2020 de los productores o importadores establecidos en el Reino Unido que hayan notificado, en el marco del Reglamento, haber comercializado legalmente hidrofluorocarburos desde el 1 de enero de 2015 [notificada con el número C(2018) 8801].

Se aprobaron asimismo cuatro Decisiones ejecutivas en el ámbito de tecnologías innovadoras dirigidas a la reducción de las emisiones de $\mathrm{CO}_{2}$ :

- Decisión de Ejecución (UE) 2018/1876 de la Comisión, de 29 de noviembre de 2018, relativa a la aprobación de la tecnología utilizada en alternadores eficientes de $12 \mathrm{~V}$ destinados a vehículos comerciales ligeros equipados con motores de combustión convencionales como tecnología innovadora para la reducción de las emisiones de $\mathrm{CO} 2$ de los vehículos comerciales ligeros, de conformidad con el Reglamento (UE) n. ${ }^{\circ}$ 510/2011 del Parlamento Europeo y del Consejo.

- Decisión de Ejecución (UE) 2018/2079 de la Comisión, de 19 de diciembre de 2018, relativa a la aprobación de la función de conducción a vela con motor al ralentí como tecnología innovadora para reducir las emisiones de $\mathrm{CO} 2$ de los turismos, de conformidad con el Reglamento (CE) n. ${ }^{\circ} 443 / 2009$ del Parlamento Europeo y del Consejo.

- Decisión de Ejecución (UE) 2019/313 de la Comisión, de 21 de febrero de 2019, relativa a la aprobación de la tecnología utilizada en un motogenerador de alta eficiencia de $48 \mathrm{~V}(\mathrm{BRM})$ más un convertidor $\mathrm{CC} / \mathrm{CC}$ de $48 \mathrm{~V} / 12 \mathrm{~V}$ de SEG Automotive Germany $\mathrm{GmbH}$ para su uso en vehículos comerciales ligeros con motor de combustión convencional y en determinados vehículos comerciales ligeros híbridos como tecnología innovadora para la reducción de las emisiones de CO2 de los vehículos comerciales ligeros, de conformidad con el Reglamento (UE) n. ${ }^{\circ}$ 510/2011 del Parlamento Europeo y del Consejo.

- Decisión de Ejecución (UE) 2019/314 de la Comisión, de 21 de febrero de 2019, relativa a la aprobación de la tecnología utilizada en un motogenerador de alta eficiencia de $48 \mathrm{~V}(\mathrm{BRM})$ más un convertidor $\mathrm{CC} / \mathrm{CC}$ de $48 \mathrm{~V} / 12 \mathrm{~V}$ de SEG 
Automotive Germany $\mathrm{GmbH}$ para su uso en turismos con motor de combustión convencional y en determinados turismos híbridos como tecnología innovadora para la reducción de las emisiones de $\mathrm{CO} 2$ de los turismos, de conformidad con el Reglamento (CE) n. ${ }^{\circ}$ 443/2009 del Parlamento Europeo y del Consejo.

Aún el ámbito de los contaminantes atmosféricos y en relación a las emisiones de gases que afectan la capa de ozono se aprobó la Decisión de Ejecución (UE) 2018/2029 de la Comisión, de 18 de diciembre de 2018, por la que se determinan los límites cuantitativos y se asignan cuotas de sustancias reguladas en el marco del Reglamento (CE) n. ${ }^{\circ}$ 1005/2009 del Parlamento Europeo y del Consejo, sobre sustancias que agotan la capa de ozono, para el período comprendido entre el 1 de enero y el 31 de diciembre de 2019 [notificada con el número C(2018) 8655].

En el ámbito de la producción de biocarburantes y biolíquidos se aprobaron tres Decisiones de ejecución:

- Decisión de Ejecución (UE) 2018/1854 de la Comisión, de 27 de noviembre de 2018, sobre el reconocimiento del régimen voluntario «Better Biomass» para demostrar el cumplimiento de los criterios de sostenibilidad de conformidad con las Directivas 98/70/CE y 2009/28/CE del Parlamento Europeo y del Consejo. Será aplicable hasta el hasta el 18 de diciembre de 2023.

- Decisión de Ejecución (UE) 2018/1984 de la Comisión, de 13 de diciembre de 2018, sobre el reconocimiento del "Sistema KZR INiG» para demostrar el cumplimiento de los criterios de sostenibilidad de conformidad con las Directivas 98/70/CE y 2009/28/CE del Parlamento Europeo y del Consejo. Será aplicable hasta el 3 de enero de 2024.

- Decisión de Ejecución (UE) 2019/142 de la Comisión, de 29 de enero de 2019, sobre el reconocimiento del régimen «U.S. Soybean Sustainability Assurance Protocol» para demostrar el cumplimiento de los criterios de sostenibilidad de conformidad con las Directivas 98/70/CE y 2009/28/CE del Parlamento Europeo y del Consejo.

En el ámbito de la legislación contra la contaminación se aprobaron las siguientes Decisiones de ejecución: 
- Decisión de Ejecución de la Comisión, de 10 de octubre de 2018, por la que se establece la respuesta definitiva, en nombre de la Unión, relativa a la importación futura de determinados productos químicos de conformidad con el Reglamento (UE) n. ${ }^{\circ}$ 649/2012 del Parlamento Europeo y del Consejo y se modifica la Decisión de Ejecución C (2016) 747 de la Comisión.

- Decisión de Ejecución (UE) 2018/1790 de la Comisión, de 16 de noviembre de 2018, que deroga la Decisión 2002/623/CE, por la que se establecen unas notas de orientación sobre la evaluación del riesgo para el medio ambiente de los organismos modificados genéticamente [notificada con el número $C(2018)$ 7513].

- Decisión de Ejecución (UE) 2018/1928 de la Comisión, de 6 de diciembre de 2018, por la que se concede a Dinamarca una exención, solicitada de conformidad con la Directiva 91/676/CEE del Consejo, relativa a la protección de las aguas contra la contaminación producida por nitratos de fuentes agrarias [notificada con el número C (2018) 8081].

- Decisión de Ejecución (UE) 2018/2013 de la Comisión, de 14 de diciembre de 2018, sobre la identificación del 1,7,7-trimetil-3-(fenilmetilen) biciclo [2.2.1]heptan-2-ona (3-benciliden-alcanfor) como sustancia extremadamente preocupante con arreglo al artículo 57, letra f), del Reglamento (CE) n. ${ }^{\circ}$ 1907/2006 del Parlamento Europeo y del Consejo.

Se actualizó en dos ocasiones la lista de instalaciones de reciclado de buques autorizadas, actividad controlada por la Comisión debido a sus potenciales afectaciones tanto en la salud humana como en el medioambiente tal y como determina el Reglamento (UE) $n^{\circ} 1257 / 2013$ del Parlamento Europeo y del Consejo:

- Decisión de Ejecución (UE) 2018/1478 de la Comisión, de 3 de octubre de 2018, por la que se modifica la Decisión de Ejecución (UE) 2016/2323 para actualizar la lista europea de instalaciones de reciclado de buques establecida con arreglo al Reglamento (UE) n. ${ }^{\circ} 1257 / 2013$ del Parlamento Europeo y del Consejo.

- Decisión de Ejecución (UE) 2018/1906 de la Comisión, de 30 de noviembre de 2018, por la que se modifica la Decisión de Ejecución (UE) 2016/2323 para 
actualizar la lista europea de instalaciones de reciclado de buques establecida con arreglo al Reglamento (UE) n. ${ }^{\circ} 1257 / 2013$ del Parlamento Europeo y del Consejo.

En el ámbito de la protección de la biodiversidad se han actualizado las listas de lugares considerados de importancia comunitaria incluidos en la red Natura 2000. Un total de ocho Decisiones ejecutivas actualizan la lista de forma separada para cada zona biogeográfica:

- Decisión de Ejecución (UE) 2019/15 de la Comisión, de 14 de diciembre de 2018, por la que se adopta la tercera lista actualizada de lugares de importancia comunitaria de la región biogeográfica estépica [notificada con el número C(2018) 8522].

- Decisión de Ejecución (UE) 2019/16 de la Comisión, de 14 de diciembre de 2018, por la que se adopta la décima lista actualizada de lugares de importancia comunitaria de la región biogeográfica panónica [notificada con el número C(2018) 8523].

- Decisión de Ejecución (UE) 2019/17 de la Comisión, de 14 de diciembre de 2018, por la que se adopta la duodécima lista actualizada de lugares de importancia comunitaria de la región biogeográfica alpina [notificada con el número C(2018) 8527].

- Decisión de Ejecución (UE) 2019/18 de la Comisión, de 14 de diciembre de 2018, por la que se adopta la duodécima lista actualizada de lugares de importancia comunitaria de la región biogeográfica continental [notificada con el número C(2018) 8528].

- Decisión de Ejecución (UE) 2019/19 de la Comisión, de 14 de diciembre de 2018, por la que se adopta la duodécima lista actualizada de lugares de importancia comunitaria de la región biogeográfica atlántica [notificada con el número C(2018) 8529].

- Decisión de Ejecución (UE) 2019/20 de la Comisión, de 14 de diciembre de 2018, por la que se adopta la séptima lista actualizada de lugares de importancia comunitaria de la región biogeográfica macaronésica [notificada con el número C(2018) 8532]. 
- Decisión de Ejecución (UE) 2019/21 de la Comisión, de 14 de diciembre de 2018, por la que se adopta la duodécima lista actualizada de lugares de importancia comunitaria de la región biogeográfica boreal [notificada con el número C (2018) 8533].

- Decisión de Ejecución (UE) 2019/22 de la Comisión, de 14 de diciembre de 2018, por la que se adopta la duodécima lista actualizada de lugares de importancia comunitaria de la región biogeográfica mediterránea [notificada con el número C (2018) 8534].

\subsection{Acuerdos internacionales y posiciones en organismos internacionales}

En lo que se refiere a la participación de la Unión Europea en los organismos internacionales, al ser todos los Estados miembros de la Unión miembros a su vez de la Organización Marítima Internacional y al afectar un ámbito de competencia exclusiva de la UE, cabe mencionar la adopción de Decisión (UE) 2018/1601 del Consejo, de 15 de octubre de 2018, relativa a la posición que debe adoptarse en nombre de la Unión Europea en el $73 .^{\circ}$ período de sesiones del Comité de Protección del Medio Marino y en el $100{ }^{\circ}$ período de sesiones del Comité de Seguridad Marítima de la Organización Marítima Internacional sobre la adopción de enmiendas a la regla 14 del anexo VI del Convenio internacional para prevenir la contaminación por los buques y al Código internacional del programa mejorado de inspecciones durante los reconocimientos de graneleros y petroleros de 2011.

Asimismo, aunque la Unión Europea tiene tan solo el estatuto de observador en algunos órganos de la Organización de Aviación Civil Internacional (OACI), su ámbito de actividad afecta competencias de la UE. Es por eso que el Consejo adoptó la posición que los Estados miembros de la Unión -todos a su vez miembros de la OACl-, deben adoptar en el seno de esta última: Decisión (UE) 2018/2027 del Consejo, de 29 de noviembre de 2018, sobre la posición que debe adoptarse, en nombre de la Unión Europea, en la Organización de Aviación Civil Internacional respecto a la Primera edición de las Normas y métodos recomendados internacionales, Protección del medio ambiente - Plan de compensación y reducción de carbono para la aviación internacional (plan CORSIA). El Consejo acordó mediante esta Decisión dar pleno apoyo al plan 
CORSIA que afectará a partir del 1 de enero de 2019 a los operadores de aeronaves que produzcan emisiones anuales de CO2 superiores a 10.000 toneladas.

Por otro lado, desde la perspectiva de la participación de la Unión Europea en los convenios internacionales y al afectar a las competencias de la Unión Europea, se adoptó la Decisión (UE) 2018/1730 del Consejo, de 12 de noviembre de 2018, relativa a la posición que se ha de tomar en nombre de la Unión Europea en la segunda reunión de la Conferencia de las Partes en el Convenio de Minamata sobre el Mercurio con respecto a la adopción de las directrices sobre el almacenamiento provisional ambientalmente racional de mercurio, distinto del mercurio de desecho, a las que se hace referencia en el artículo 10, apartados 2 y 3 , de dicho Convenio.

\section{OTRAS ACTIVIDADES Y ACTOS EN EL ÁmBITO DE LA POLÍTICA EUROPEA DEL MEDIO AMBIENTE}

\subsection{Consultas públicas}

Durante el período objeto de esta crónica la Comisión llevó a cabo cinco consultas públicas en el ámbito del medio ambiente.

Por último, se lanzó una consulta pública en el marco de la iniciativa "Revising the rules for free allocation in the EU Emissions Trading System" durante el 20 de marzo y el 17 de abril de 2019. La Comisión debe desarrollar la regulación del comercio de derechos de emisión para el periodo 2021-2030. La consulta pública pregunta específicamente para el ámbito de la asignación libre de derechos de emisión en función de los cambios en e nivel de actividad.

La iniciativa "Towards an EU Product Policy Framework contributing to the Circular Economy" estuvo abierta a consulta pública entre el 29 de noviembre de 2018 y el 24 de enero de 2019. Su objetivo era recabar información respecto las decisiones de los consumidores a la hora de comprar productos con el objetivo de contribuir al Plan de Acción para la Economía Circular adoptada por la Comisión en 2015 (COM (2015)614 final). 
La iniciativa "Evaluation of the Eel Regulation" estuvo abierta a consulta pública entre el 14 de diciembre de 2018 y el 8 de marzo de 2019. El objetivo era conocer la opinión de la sociedad sobre la regulación para la protección y recuperación de la anguila.

Se hizo también una consulta pública en relación a la inciativa "EU implementation of the Aarhus Convention in the area of access to justice in environmental matters", que estuvo abierta entre el 20 diciembre y el 14 de marzo. Después que el Comité de control del cumplimiento de la Convención de la que son parte tanto la UE como los Estados miembros- considerara que esta no se estaba aplicando debidamente, la Comisión lanzó una consulta pública dirigida a todos actores involucrados para proveer una imagen completa del estado de la cuestión de su aplicación. Esta consulta forma parte de un estudio de análisis sobre el acceso a la justicia medioambiental y la aplicación de la Convención por parte de la UE en este ámbito.

La iniciativa "Deforestation and forest degradation - stepping up EU action" pretende cimentar las bases para un acercamiento integrador al problema de la deforestación y sus graves causas. Entre el 14 de enero y el 25 de febrero estuvo abierta una consulta pública para recoger las ideas de los actores afectados consistentes tanto en la mejor comprensión del fenómeno como de potenciales soluciones.

\subsection{Resoluciones no legislativas del Parlamento Europeo}

Durante este período el Parlamento Europeo ha aprobado nueve resoluciones no legislativas que afectan al objeto de interés de esta crónica.

En el ámbito de la lucha por el cambio climático el PE aprobó el 25 de octubre de 2018 la "Resolución del Parlamento Europeo, de 25 de octubre de 2018, sobre la Conferencia de las Naciones Unidas sobre el Cambio Climático de 2018 (COP24) en Katowice (Polonia)". Hace un llamamiento a la Comisión y a los Estados miembros a hablar con una voz única en la COP24 y a incluir el cambio climático en otros foros multilaterales, así como a llevar a cabo un liderazgo internacional en la lucha por el clima predicando con el ejemplo y subraya en ese sentido la necesidad de invertir más en la mitigación y en la adaptación al cambio 
climático. También reclama formar parte de la delegación de la UE en la COP24 y tener acceso a toda la documentación preparatoria desde el inicio.

Temáticamente relacionada con la anterior, también el 25 de octubre de 2018 se aprobó la resolución no legislativa "Resolución del Parlamento Europeo, de 25 de octubre de 2018, sobre la implantación de una infraestructura para los combustibles alternativos en la Unión: ¡es tiempo de actuar!". En ella el Parlamento Europeo lamenta la excesivamente lenta progresión de la implantación de las infraestructuras para el uso de combustibles alternativos y pide a la Comisión que impulse su uso en aeropuertos, que acelere la descarbonización del sector marítimo, tanto en el mar como en las infraestructuras portuarias, y pide asimismo que lleve a cabo evaluaciones del ciclo de vida de todos los combustibles alternativos a fin de poder medir su impacto.

También vinculado a la lucha contra el cambio climático el Parlamento Europeo aprobó la resolución "Resolución del Parlamento Europeo, de 28 de marzo de 2019, sobre la evolución reciente del escándalo del «Dieselgate»". El PE se queja de la falta de cooperación por parte de la Comisión en la comisión de investigación parlamentaria sobre este asunto y le pide que no relaje los límites de emisiones que han de cumplir los vehículos para su certificación. A los Estados miembros les pide que retiren cuanto antes del mercado los vehículos afectados y que adapten cuanto antes los vehículos afectados ya en funcionamiento en colaboración con los fabricantes.

Se aprobó en el ámbito de la mejora del aire la "Resolución del Parlamento Europeo, de 13 de marzo de 2019, sobre una Europa que protege: aire puro para todos". Desde una consideración amplia de la calidad del aire, la resolución insta a la Comisión a actuar en varios ámbitos para reducir la polución ambiental, incluyendo el transporte, la agricultura, la energía y la contaminación en espacios cerrados. Además, anima a los Estados miembros y la Comisión a incentivar la investigación sobre la contaminación del aire y a eliminar subsidios o incentivos fiscales a tecnologías o actividad económica altamente contaminante.

En el ámbito de la protección de la biodiversidad se aprobó la "Resolución del Parlamento Europeo, de 25 de octubre de 2018, sobre la 14. ${ }^{a}$ reunión de la 
Conferencia de las Partes del Convenio sobre la Diversidad Biológica (CoP14)". El Parlamento Europeo denuncia aquí que las Metas de Aichi para la Diversidad Biológica para 2020 no se podrán conseguir debido al ritmo de destrucción de la biodiversidad que se está teniendo lugar a lo largo de la década.

Durante el período de tiempo analizado también se ha aprobado una resolución relativa a la industria alimentaria cárnica: "Resolución del Parlamento Europeo, de 25 de octubre de 2018, sobre el bienestar de los animales, el uso de agentes antimicrobianos y el impacto medioambiental de la cría industrial de pollos de engorde". El Parlamento Europeo señala la deficiente aplicación de la Directiva 2007/43/CE y las consecuencias en el bienestar de los pollos destinados a la producción de carne, por lo que anima a la Comisión a que tome ciertas medidas para garantizar unas mejores condiciones en las granjas, que mejore el control de productos importados de este tipo y que se imponga un sistema comunitario similar al de los huevos de gallina para comunicar al consumidor los estándares de producción del producto.

En el ámbito fitosanitario se aprobó la "Resolución del Parlamento Europeo, de 16 de enero de 2019, sobre el procedimiento de autorización de la Unión para los plaguicidas", fruto de la preocupación que suscitó el informe de la Comisión Especial sobre el Procedimiento de Autorización de la Unión para los Plaguicidas en relación a aplicación del Reglamento (CE) n. 1107/2009, norma que armoniza las normas de comercialización de productos fitosanitarios. En relación a esta cuestión el PE hace un seguido de peticiones a la Comisión y a los Estados miembros para una aplicación más adecuada de dicho Reglamento.

El ámbito de la política pesquera a motivado por su lado dos resoluciones no legislativas del Parlamento Europeo relativas a acuerdos pesqueros con terceros países: la "Resolución legislativa del Parlamento Europeo, de 12 de febrero de 2019, sobre el proyecto de Decisión del Consejo relativa a la celebración del Acuerdo de colaboración de pesca sostenible entre la Unión Europea y el Reino de Marruecos, de su Protocolo de aplicación y del Canje de Notas adjunto al Acuerdo" y la "Resolución no legislativa del Parlamento Europeo, de 12 de febrero de 2019, relativa al proyecto de Decisión del Consejo sobre la 
celebración del Protocolo relativo a la aplicación del Acuerdo de Asociación en el sector pesquero entre la Unión Europea y la República de Costa de Marfil".

\subsection{Informes y comunicaciones de la Comisión Europea}

Varios de los informes de la Comisión consisten en explicar aspectos relativos a la aplicación de normas europeas en el ámbito del medio ambiente:

- Informe de la Comisión al Parlamento Europeo y al Consejo relativo a la aplicación de la estrategia de adaptación al cambio climático de la UE. El informe analiza los efectos del cambio climático y los resultados de las medidas llevadas a cabo en la lucha contra este en el marco de la estrategia de adaptación al cambio climático de 2013. Aunque las perspectivas en relación al cambio climático no son halagüeñas, el informe subraya la conveniencia de la existencia de una estrategia de adaptación.

- Informe de la Comisión al Parlamento Europeo y al Consejo sobre la aplicación de la Directiva marco sobre el agua (2000/60/CE) y la Directiva sobre inundaciones (2007/60/CE). Segundos planes hidrológicos de cuenca. Primeros planes de gestión del riesgo de inundación. Tras hacer un balance de dichos planes, el informe concluye que a pesar de que se ha mejorado en ciertos aspectos relativos al cumplimiento de la Directiva marco como sería el recibimiento a tiempo de los informes por parte de los Estados miembros, hace falta incrementar los esfuerzos en la aplicación de la legislación.

- Informe de la Comisión al Parlamento Europeo, al Consejo, al Comité Económico y Social Europeo y al Comité de las Regiones sobre la revisión y actualización del segundo plan de aplicación de la Unión Europea de conformidad con el artículo 8, apartado 4, del Reglamento (CE) n. ${ }^{\circ}$ 850/2004 sobre contaminantes orgánicos persistentes. El plan de aplicación sobre el que da cuentas este informe se hizo para dar respuesta a la inclusión de una serie de nuevos contaminantes orgánicos persistentes en el Convenio de Estocolmo y los avances técnicos y legislativos realizados en la materia. Concluye que hace falta más coordinación e información entre la Comisión y los Estados miembros para su efectiva aplicación. 
- Informe de la Comisión al Consejo y al Parlamento Europeo. Informe de situación sobre la aplicación del Plan de acción de la UE contra el tráfico de especies silvestres. El informe da una visión general de la aplicación del plan de acción a partir de la información aportada por los Estados miembros y las diferentes agencias europeas implicadas.

Otro grupo importante de informes realizados por la Comisión son los dedicados a explicar el uso de poderes legislativos delegados a esta:

- Informe de la Comisión al Parlamento Europeo y al Consejo sobre el ejercicio de la delegación otorgada a la Comisión con arreglo al Reglamento (CE) n. ${ }^{\circ}$ 443/2009 por el que se establecen normas de comportamiento en materia de emisiones de los turismos nuevos como parte del enfoque integrado de la Unión para reducir las emisiones de $\mathrm{CO} 2$ de los vehículos ligeros. La Comisión afirma que desde que empezó a hacer uso de esta delegación en 2009 no ha habido objeciones por parte del Parlamento o del Consejo.

- Informe de la Comisión al Parlamento Europeo y al Consejo sobre la aplicación del Reglamento (CE) n. ${ }^{\circ}$ 1013/2006, relativo a los traslados de residuos Generación, tratamiento y traslado transfronterizo de residuos peligrosos y otros residuos en los Estados miembros de la Unión Europea, 2013-2015; ejercicio de los poderes para adoptar actos delegados. El documento informa sobre tres aspectos del traslado de residuos: la información y calidad de los datos, los traslados de residuos en sí y los traslados ilícitos.

- Informe de la Comisión al Parlamento Europeo y al Consejo sobre el ejercicio de los poderes para adoptar actos delegados otorgados a la Comisión de conformidad con el Reglamento (UE) n. ${ }^{\circ} 1143 / 2014$ del Parlamento Europeo y del Consejo, de 22 de octubre de 2014, sobre la prevención y la gestión de la introducción y propagación de especies exóticas invasoras. La Comisión considera que el uso de la delegación de poderes se ha hecho correctamente y que es conveniente mantenerla en el futuro.

- Informe de la Comisión al Parlamento Europeo y al Consejo sobre el ejercicio de los poderes delegados en la Comisión de conformidad con el Reglamento (UE) n. ${ }^{\circ}$ 995/2010 del Parlamento Europeo y del Consejo, de 20 de octubre de 
2010, por el que se establecen las obligaciones de los agentes que comercializan madera y productos de la madera (el Reglamento de la UE sobre la madera).

- Informe de la Comisión al Consejo y al Parlamento Europeo sobre el ejercicio del poder para adoptar actos delegados otorgado a la Comisión en el marco de la Directiva 2008/105/CE relativa a las normas de calidad ambiental en el ámbito de la política de aguas. La Comisión no ha hecho uso de esta delegación, pero considera que podría querer hacerlo en el futuro.

A parte de los tipos descritos anteriormente, la Comisión elaboró otros cuatro informes sobre temas de diversa índole:

- Informe de la Comisión al Parlamento Europeo y al Consejo. La UE y el Acuerdo de París sobre cambio climático: balance del progreso logrado en la COP de Katowice (exigido conforme al artículo 21 del Reglamento (UE) n. ${ }^{\circ}$ 525/2013 del Parlamento Europeo y del Consejo, de 21 de mayo de 2013, relativo a un mecanismo para el seguimiento y la notificación, a nivel nacional o de la Unión, de otra información relevante para el cambio climático, y por el que se deroga la Decisión n. ${ }^{\circ}$ 280/2004/CE). En este extenso informe se hace una explicación detallada de la actividad de la UE desde la aprobación del Acuerdo de París en 2016 hasta la actualidad el ámbito de la lucha contra el cambio climático.

- Informe de la Comisión al Parlamento Europeo, al Consejo, al Comité Económico y Social Europeo y al Comité de las Regiones. Resumen del informe de síntesis sobre el funcionamiento del Reglamento (UE) n. ${ }^{\circ}$ 649/2012, relativo a la exportación e importación de productos químicos peligrosos. El informe concluye que en general los procedimientos establecidos por el Reglamento en cuestión han sido efectivos y que han conseguido sus objetivos, tanto por lo que respecta a los procedimientos de notificación como los de consentimiento expreso.

- Informe de la Comisión al Parlamento Europeo y al Consejo. Reglamento (UE) n. $995 / 2010$ del Parlamento Europeo y del Consejo, de 20 de octubre de 2010, por el que se establecen las obligaciones de los agentes que comercializan madera y productos de la madera (el Reglamento de la UE sobre la madera). Informe bienal para el período de marzo de 2015 a febrero de 2017. 
- Informe de la Comisión al Parlamento Europeo y al Consejo. Informe sobre el mercado europeo del carbono. Elaborado para dar cumplimiento a la Directiva 2003/87/CE, por la que estos tienen que publicarse con carácter anual, este informe explica cuales han estados los progresos en la reforma del régimen de comercio de derechos de emisión de la Unión Europea.

Por otro lado, la Comisión realizó cuatro Comunicaciones temáticamente relevantes para esta crónica:

- Comunicación de la Comisión al Parlamento Europeo, al Consejo Europeo, al Consejo, al Comité Económico y Social Europeo, al Comité de las Regiones y al Banco Europeo de Inversiones. Un planeta limpio para todos. La visión estratégica europea a largo plazo de una economía próspera, moderna, competitiva y climáticamente neutra. La Comunicación hace un repaso de los efectos del cambio climático en los diferentes ámbitos de la vida humana y desarrolla los medios por los que los Estados miembros y la Unión pueden ayudar a frenarlo, ya sea con el uso de energías renovables hasta un liderazgo internacional en el ámbito climático.

- Comunicación de la Comisión al Parlamento Europeo, al Consejo, al Comité Económico y Social Europeo y al Comité de las Regiones. Una bioeconomía sostenible para Europa: consolidar la conexión entre la economía, la sociedad y el medio ambiente. Esta Comunicación actualiza la Estrategia de Bioeconomía de 2012, que ya se revisó a su vez en 2017, y presenta el conjunto de 14 acciones que a partir de 2019 se van a llevar a cabo por tal de aprovechar las potencialidades de la bioeconomía a los retos que enfrenta la UE en ámbitos tales como el cambio climático.

- Comunicación de la Comisión al Parlamento Europeo, al Consejo y al Comité Económico y Social Europeo. Enfoque estratégico de la Unión Europea en materia de productos farmacéuticos en el medio ambiente. Esta Comunicación da cumplimiento a la obligación establecida por la Directiva 2008/105/CE de proporcionar un enfoque estratégico sobre la contaminación por productos farmacéuticos. También aborda el problema de la resistencia a los antimicrobianos.

- Comunicación de la Comisión al Parlamento Europeo, al Consejo, al Comité 
Económico y Social Europeo y al Comité de las Regiones. Hacia un marco de la Unión Europea más exhaustivo en materia de alteradores endocrinos. Esta Comunicación se realiza a partir de una petición del Parlamento Europeo y del Consejo. En primer lugar, se describen los progresos científicos logrados en materia de alteradores endocrinos en los últimos veinte años, en segundo lugar, se resumen las acciones que la UE ha adoptado hasta ahora y por último se expone el planteamiento que propone la Comisión para avanzar en la política de la UE en materia de alteradores endocrinos.

\subsection{Dictámenes del Comité de las Regiones y del Comité Económico y Social Europeo}

A parte de los Dictámenes realizados por el Comité Europeo de las Regiones y el Comité Económico y Social Europeo como parte de los procesos legislativos comunitarios, hay que mencionar los tres Dictámenes hechos por iniciativa propia en el ámbito de la política medioambiental:

- Dictamen del Comité Europeo de las Regiones - La contribución de las ciudades y regiones de la UE a la COP14 del CDB y la Estrategia de la UE sobre la Biodiversidad después de 2020. Este Dictamen expresa la visión del Comité Europeo de las Regiones a la luz de los avances en materia de acción climática en vistas a la consecución de los objetivos para 2030 y analiza las formas en que las entidades locales y regionales pueden contribuir a dichos objetivos.

- Dictamen del Comité Económico y Social Europeo sobre el «Pacto Europeo de Financiación Climática» (Dictamen de iniciativa). El Comité Económico y Social Europeo defiende aquí la necesidad de reformar el sistema económico europeo para tender a la cooperación y la convergencia en lugar de la competencia. Según este, solo si un Europa adopta esta perspectiva a largo plazo será posible una financiación que integre la perspectiva de la lucha contra el cambio climática de forma efectiva. A partir de aquí hace un conjunto de propuestas de ámbitos de inversión conducentes a este objetivo.

- Dictamen prospectivo del Comité Europeo de las Regiones - La gobernanza climática después de 2020 desde una perspectiva europea y global: contribución a la COP24 de la CMNUCC. En este el Comité Europeo de las Regiones expresa su preocupación por el deterioro de la biodiversidad en el mundo y por el 
previsible incumplimiento de los compromisos tomados en el Plan Estratégico para la Diversidad Biológica 2011-2020 del Convenio sobre la Diversidad Biológica y la correspondiente Estrategia de la UE sobre la Biodiversidad 2020. Todo seguido hace un llamamiento a la Comisión i a los Estados miembros a tomar un conjunto de medidas y a redoblar los esfuerzos en ámbitos como la financiación climática.

\section{PROCEDIMIENTOS DE INFRACCIÓN}

Durante el período de tiempo cubierto por esta crónica dos procesos de infracción de la legislación europea medioambiental iniciados por la Comisión han terminado llegando al Tribunal de Justicia de la Unión Europea. En primer lugar, encontramos el incumplimiento de las normas de la UE en materia de prevención de inundaciones establecidas en la Directiva 2007/60/CE. El 22 de marzo de 2016 era la data límite para la publicación y notificación a la Comisión de los planes de gestión del riesgo de inundación. Al persistir España en el incumplimiento tras el envío de una carta de emplazamiento por parte de la Comisión que instaba a presentar los planes de gestión del riesgo de inundación para siete demarcaciones hidrográficas de las Islas Canarias, el 24 de enero de 2019 la Comisión decidió llevar el caso al Tribunal de Justicia de la UE.

En segundo lugar, encontramos el incumplimiento de España de la Directiva 2000/60/CE en no proteger las masas de aguas subterráneas que alimentan el humedal de Doñana. Siendo Doñana uno de los humedales más grandes de Europa y teniendo una gran diversidad de ecosistemas, motivo por el que se han declarado varias de sus zonas como lugares Natura 2000, este incumplimiento afecta también la Directiva sobre hábitats (Directiva 92/43/CEE del Consejo) y de la Directiva sobre aves (Directiva 2009/147/CE). Debido a la insuficiencia de las medidas de conservación tomadas por España de acuerda a estas normas y a la deficiencia de la aplicación de estas mismas medidas la Comisión decidió llevar España, también el 24 de enero de 2019, ante el Tribunal de Justicia de la UE. 